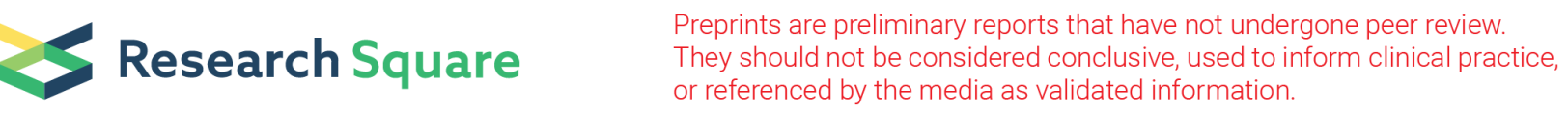

\title{
Improving the Conductivity and its Flexibility of Fabricated Chips from A copolymer PDMS-PEI and Nano Graphene Metals composite
}

\section{Ameen Abdelrahman ( $\nabla$ abda02@uqat.ca )}

UQAT: Universite du Quebec en Abitibi Temiscamingue https://orcid.org/0000-0002-7177-2687

\section{Fouad Erchiqui}

UQAT: Universite du Quebec en Abitibi Temiscamingue

Mourad Nedil

UQAT: Universite du Quebec en Abitibi Temiscamingue

\section{Research Article}

Keywords: Copolymers, Impedance, Assembled metals, Graphene, Self-Healing

Posted Date: May 14th, 2021

DOl: https://doi.org/10.21203/rs.3.rs-507170/v1

License: (c) (i) This work is licensed under a Creative Commons Attribution 4.0 International License.

Read Full License 


\section{Abstract}

Our work aims to make a unique polymer to be used as a conductive and flexible chip antenna. Its properties are robustness, rigidity, stretchability, and good conduction. The fabricated composite is composed of two copolymers, Polydimethylsiloxane (PDMS) and Polyethylenimine (PEI), assembled with nano metals (Copper, Silver ), and graphene nanoparticles as a matrix. Nano metals fill out the inter-layer space, and polymer voids reinforce the cross linker. Graphene/metal nanoparticles help make chelating complexes using metallic bonds, enhancing the polymer's conductivity from $1.87 \times 10^{-4}$ to $5.64 \times 10^{-6} \sigma$ $\mathrm{Scm}^{-1}$. We analyze the conductivity, self-healing, and surface morphology of fabricated composite using different spectroscopic techniques, such as electrochemical impedance (EIS), Scanning Electronic Microscopy ( SEM), Transition Electronic Microscopy (TEM), Infrared spectroscopy ( IR), UV-Visible spectroscopy (UV), and a particle size analyzer.

\section{Introduction}

Flexible (stretchable) electronics fabricated with electronic innovation technology incorporates an organic/inorganic conductive component with nonconductive polymers or metal deposits substrates. Stretchable electronics have gotten much attention due to their unique properties like efficiency, flexibility/ductility, low-cost cook-up processes, and broader application potential in displays, biosensors, RFID, wearable antenna tags, and devices [1]. One important value of stretchable electronics is that materials keep conductivity under great strain during mechanical movement. The highly diverse properties of polymeric materials such as healing, flexibility, robustness, and conductivity are the main reasons they are applicable in different fields. They are particularly useful when integrated or impregnated with different materials, like silver nanowire (AgNW) [2,3], carbon nanotubes (CNT) $[4,5]$, graphene (GR) [6-9], polyaniline (PANI)(10), or polypyrrole (PPY) [11,12].

Poly(dimethylsiloxane) (PDMS) is one of the most likely di-electric materials used to fabricate microfluidic electronic devices. The material's cost, simple fabrication process, rapid prototyping, excellent optical transparency, and gas permeability have been widely publicized. Although PDMS has many advantages, its high hydrophobicity (water contact angle $\sim 108^{\circ} \pm 7^{\circ}$ ) usually limits its applications. Recently, copolymers have been getting more attention due to their applications in aerospace, microelectronics, printed circuits, adhesives, thermoplastic elastomers, and organophilic pervaporation [13-16]. Furthermore, the high demand for microelectronics and nanoelectronic devices increases because they are highly-precious and used to control dimensional structures in wafer-scale manufacturing [17-20 ]. The device invention methodologies are already well known in electronic manufacture using silicon chips miniaturization on a large scale [21-22].

On the other hand, alternative methodology builds on approaches to block copolymer (BCP) as selfassembly nanostructure creation is increasingly and rapidly approached by researchers [23]. Approaches can create sub-10 nm structures with low costs [24, 25]. BCPs like polyethyleneimine -bpolymethylmethacrylate (PEI-b-PMMA), polylactic acid-b-polystyrene (PLA-b-PS), polystyrene-b- 
polydimethylsiloxane(PS-b-PDMS), and polyethylene oxide-b-polystyrene (PEO-b-PS) of cylindrical, lamellar, or spherical structure joints in different strategies to modify or control the substrate and alignment pattern have been used to pioneer nano lithographic disassembly [26, 27]. However, conventional conductors are not stretchable, while traditional elastomers like polystyrene, natural rubber (NR), and poly(dimethylsiloxane) (PDMS) are not conducive. Two methods have been used to achieve stretchable interconnected interlink filler. The first involves making wavy or mesh configurations by adding conductive materials, materials with tensile strain, and elastic materials [28]. The second method involves filling the gaps or interspace of polymers with conducting material $[29,30]$.

Copolymerization is one of the best ways to prepare new polymeric materials. By combining two structures, its specific properties have different chemical or physical properties as one block polymer chain. It has been established that the integration between polysiloxane and polyimide improves efficiency and polyimide's processability and its mechanics augment polysiloxane's properties. The other beneficial properties of poly(imide siloxane) copolymers should be considered, high hydrophobicity, oxidizing resistance to other oxidizing agents and environment, and adhesion di-electric constants, high flexibility, and robustness [31-37]. Moreover, the stability (thermoplastics to thermoplastic elastomers) of poly(imide siloxane) copolymers, which based on composition and structure[38, 39]. Therefore, the copolymers have become highly sought after for many application such as microelectronic, adhesives, biosensors, communication, and aerospace applications [31, 35, 39].

PDMS is characterized by a low glass transition temperature of $-127^{\circ} \mathrm{C}$, in addition to the shear elastic modulus $250 \mathrm{kPa}$, while a specific gravity range between 0.91 to 1.00 with a molecular weight of $10-60$ $\times 10^{3} \mathrm{gmol}-1$. PDMS is an inert polymer and hydrophobic chemical environment partially dissolved in solvents such as pentane, xylene, and trimethylamine [40]. Studies show that carbon nanotubes (CNTs) have an electrical conductivity of $10^{4}-10^{5} \mathrm{~S} \mathrm{~cm}-1$, high carrier mobility of $1000-4000 \mathrm{~cm}^{2} \mathrm{~V}^{-1} \mathrm{~s}^{-1}$, thermal stability up to $700^{\circ} \mathrm{C}$ in air Young's models of between $0.27-1.25 \mathrm{TPa}$, and thermal conductivity of 3000-6600 W m-1 K-1 [41-43]. The electrically conductive CNT/polymer composites have potential applications, especially in electromagnetic shielding,[44, 45] energy harvesting, biomedical devices., supercapacitors, [46, 47] sensors, [ 48,49$]$ and smart actuators [50, 51]. Since CNT/polymer composites are mechanically resilient, cost-effective, lightweight, easily process able, scalable, and compliant, they can be used in electric heating elements [16-18]. Polydimethylsiloxane (PDMS), a type of silicon-based elastomer, has excellent properties, including optical transparency, chemical/biological extinction, flexibility, nontoxicity, and gas permeability $[53,54]$. PEI (polyethyleneimine) is applicable in different industries. Its various properties, like water base polymer selectivity (it dissolves in hot water), give it good chemical and thermal stability and mechanical properties [55]. Different studies have been done on the assembly of a PEI/metal complex. For instance, Kurdi and Tremblayas' work on hollow fiber membranes used $\mathrm{O}_{2} / \mathrm{N}_{2}$ adsorption on the surfaces [56]. Ren et al. have also studied the effect of different solvents on PEl's morphology [57].

This paper aims to describe the fabrication of a flexible conductor copolymer composed of polyethyleneimine and polydimethylsiloxane assembled in a thin layer of graphene and nanoparticulate 
metals made from silver and copper. Various characterizations have been conducted on copolymers to evaluate which composite can produce a flexible, stretchable antenna in future work.

\section{Materials And Methods}

\subsection{Materials}

Graphene Nano powders (purity $>$ 99\%, 300 mesh) were supplied by Sigma-Aldrich Co., Ltd. (Canada). Most of the others chemicals(, $\mathrm{CuSO}_{4}, \mathrm{AlCl}_{3}$ and $\mathrm{AgNO}_{3}$, ) used for prepared electrolyte salt solution were acquired by scientific fisher Toronto, Canada . . Polyethylenimine (PEI), n-Hexane, and THF were purchased from Sigma Aldrich, Canada. Polydimethylsiloxane (PDMS) was purchased from Sylgard R 184, Dow Corning Corporation, and Canada.

\subsection{Methods}

\subsubsection{Assembly of Nano Graphene on PDMS}

By taken specific quantities of $3 \mathrm{mg} / \mathrm{mL}$ PDMS, $2 \mathrm{ml}$ of Tetrahydrofuran (THF ), and (6 mg) of Graphene Nano powder was added to a $100 \mathrm{ml}$ glass beaker and mixed until homogenous using an XHFDY homogenizer at $3500 \mathrm{rpm}$ for 15 minutes. The colloidal solution was then further mixed using ultrasonication with adjustable $\mathrm{t}$ temperature at $45^{\circ} \mathrm{C}$ for one hour.

\subsubsection{Preparation of the PEl composites matrix}

We took $3 \mathrm{ml}$ of $0.2 \mathrm{M}$ electrolyte solution, $\mathrm{CuSO} 4, \mathrm{Al} \mathrm{Cl}_{3}$ and $\mathrm{AgNO}_{3}$, and heated it until $40^{\circ} \mathrm{C}$. Then we added PEl (dissolved in hot water), after that stirring for 5 hours. Ultra sonication was used until homogeneous, and the complete dispersal of NPs inside polymers chains occurred.

\subsubsection{Copolymers (PEI -g-PDMS) molding}

A percent (50 v /50v) of PDMS/Graphene and composites was mixed in a PEl solution, then curing agent $B$ was added in a weight ratio of 10:1 of total volume, The mixture was put under a vacuum oven at room temperature for 30 minutes to remove the bubbles completely, and then it was picked at $60^{\circ} \mathrm{C}$ for four hours.

Afterward, from our understanding, Graphene nanomaterials have good electric properties because charged electrons move easily through carbon by forming resonance outside of the bonds $(C=C)$ that transfer the electrical charge $p$ high to permit electrical conductivity. Subsequently, adding or grafting a small number of carbon nanoparticles or Graphene alternatives to nonconductive polymers will improve the impact of their surface, increase surface area, and reduce resistivity. For that reason, polymer nanocomposites could be applied to biological sensors, electronic fabrication, or automotive and aerospace manufacturing. Extensive research on assembling or grafting different sorts of polymers by different composites ceramic or inorganic materials to improve the different characteristics of new 
composites (mechanicals, chemicals, and thermal) has been carried out. One factor should be considered: the preparation method and the process of creating the nanocomposite matrix, and physical properties like the aggregation and deposition or depletion of carbon sheets can affect its electrical performance. Nanofibers, graphene sheets, and nanotubes (SWNT or MWNT) produced by different methods, the adhesion technique, matrix alignment, the dispersion between the nanomaterial and polymer, even chemical modification and purification have a great impact on the electrical conductivity of nanocomposites.

The imaginary peak is a part of the electric modulus ( $\left.\mathrm{M}^{\prime \prime}\right)$ supply input on long-domain of dipole motion, which results from the imaginary part of the impedance spectrum (Z") (imaginary for the copolymer under discussion). The copolymer PDMS-g-PEl behaves like an electrolyte solution of different specious with dipole sites. On the other hand, there are interfaces between the nanoparticle dipoles and pairing electron on $\mathrm{N}$ atoms in $\mathrm{PEl}$, which results in circles of resonance inside graphene structure, as shown in Figure 1.

\section{Results And Discussion}

\subsection{Characterization}

FTIR spectra were acquired using a Nicolet iS50 IR spectrometer association with KBr pellets. The PDMS morphology of graphene, PEI -NPs, and copolymer were investigated using a transmission electron microscope (JEM-2100F, Japan). The Current (I)-voltage (V) curves were measured by using an electrochemical working station (AUTO LAB PGSTAT100).

\section{EIS characterization}

The detection impedance of composite materials used for electrodes EIS analysis or electrochemical analysis was investigated using a Multidetector connected with a Frequency Analyzer (MPFA). Its potentiostat-galvanostat joint with eight channels is used for electrochemical characterization and electrolytes battery studies (10V, 4A). It is designed as Corrware/Corrview system to facilitate the implementation of all electrochemical methods associated with the $1255 \mathrm{~B}$ frequency analyzer to detect or estimate OCV and CV. This is achieved by taking a thin layer or cylinder from different electrolyte polymers, then putting them in a sample shape (e.g., coin cell) sandwiched between two proper electrodes conducted through impedance at frequencies between $2 \mathrm{MHz}$ and $1.5 \mathrm{kHz}$ at open cycle voltage $(\mathrm{OCV}=$ 0.39) using three electrodes, a working electrode (glassy), a reference $\mathrm{Ag} / \mathrm{Ag} \mathrm{Cl}$ electrode and a counter electrode.

Real impedance ( $\left.Z^{\prime}\right)$ indicated the sample's ohmic resistance, while imaginary (Z") calculates non-ohmic resistance. We can summarize the EIS characterization by some inhomogeneous changes regarding the polymer conductivity. The analysis mechanism is related to any development or change of double-layer electrode, and polymer surface is visible as a minimum of Z" as a frequency function. A Nyquist plot 
curve applicable to electronic circuits is used to estimate the electrical or electrochemical parameters, especially on charge transfer and resistance in the system. See Figure 2 below.

We noticed an inverse proportion of resistance conductivity by investigating the specific resistance of different prepared compounds (PDMS-g-PEI, electrolyte Ns, PDMS-graphene, and PEI -NPS), which depends on the free of movement of ionic charges inside the compound. In the case of the liquid electrolyte ( $0.2 \mathrm{M}$ of $\mathrm{CuSO}_{4}$ and $\mathrm{AgNO}$ ), we found a lower resistance ( $\mathrm{Z}^{\prime}$ value) compared to another flexible, stretchable polymer. We also recorded that the conductivity of PEI/NPS is higher than PDMSgraphene. It might be that the NPS (Ag, $\mathrm{Cu}$ ) created new sites with an amines group (dual characterization). A pair of electrons charge the transfer, and an Ag-Ag and Cu-cu metallic bond losses an electron, and numerous electron charges feed the polymers.

On the other hand, we found that the PDMS-graphene conductivity is increased by coupling or co blocking with PEI/NPS. Our explanation for that phenomena could be that free ions created by PEI/NPs cause a Graphene resonance $(\pi-\pi)$ bond inside the grapheme structure (PDMS-graphene). Otherwise, due to nanoparticles (Ag and Copper) impregnated inside a matrix synthesis, different active sites are needed to improve charge or ions. Table 1 shows the calculation for the electric conductivity using the following expression,

$$
R=\rho \frac{L}{A} \quad \text { and } \quad \sigma=\frac{1}{\rho}=\frac{L / A}{R}
$$

Where $\rho$ indicates the material resistivity, $L$ is the material's length, $A$ is the polymer area, and L/A is the cell constant. Since R can be acquired by the EIS plot, we can detect the $\sigma$ for prepared composites polymer. The conductivity of the electrolyte solution PDMS-b-PEI-PEI-NPs-PDMS-Graphene is shown below in Table 1.

Table 1 shows the conductivity measurements of prepared materials.

\begin{tabular}{|llll|}
\hline Materials Composite & $\mathrm{L} / \mathrm{A}\left(\mathrm{cm}^{-1}\right)$ & $\mathrm{R} / \mathrm{A}\left(\Omega \mathrm{cm}^{2}\right)$ & $\sigma\left(\mathrm{S} \mathrm{cm}^{-1}\right)$ \\
\hline PDMS-b-PEI & $3.3 \times 10^{-2}$ & $6.09 \times 10^{2}$ & $1.87 \times 10^{-4}$ \\
\hline PDMS-Graphene & $2.56 \times 10^{-2}$ & $3.55 \times 10^{3}$ & $1.04 \times 10^{-5}$ \\
\hline PEI-NPs & $1.4 \times 10^{-2}$ & $4.55 \times 10^{4}$ & $3.67 \times 10^{-7}$ \\
\hline Electrolyte solution & - & - & $5.64 \times 10^{-6}$ \\
\hline
\end{tabular}

\section{Fourier transform infrared spectroscopy.}




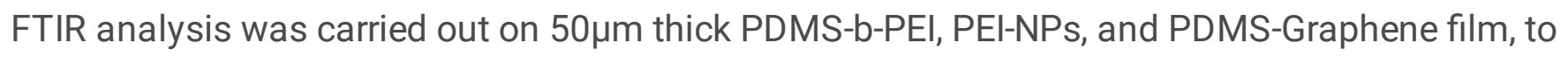
investigate the effect of grafting and assembled of composites on the properties of functional groups of polymers. The FTIR characterization was done by an Equinox FTIR Spectrometer (Billerica, MA, Bruker Optics) provided a $\mathrm{KBr}$ beam splitter. Each prepared sample has been scanned at ambient temperature with a resolution of $4 \mathrm{~cm}^{-1}$ under inert nitrogen flux flow to eliminate any water vapor. The data were recorded in the wavelength around $4000-400 \mathrm{~cm}^{-1}$ using Bruker Optics OPUS (Bruker Optics) 4.0 software.

\section{IR characterization}

Figure 3 shows a comparison between different composites of PDMS/graphene. In the FTIR spectra, we found two spectra at 845 and $1585 \mathrm{~cm}-1$ for the carbon structure of carbon in graphene, which correspond to $\mathrm{v}(\mathrm{C}=\mathrm{O})$ and corresponds to peak $1743 \mathrm{~cm}^{-1}$ at typical of carboxyl moieties. Another carboxyl group slightly appears around to $1346 \mathrm{~cm}^{-1}$. A weak peak noticed at $1575 \mathrm{~cm}^{-1}$, appoint to $-\mathrm{C}=\mathrm{C}$ in the spectrum might be resonance phenomena inside the graphene ring related to electron transfer or bi -bi bond interface interaction between graphene structure and SiO3 of PDMS polymer at band $785 \mathrm{~cm}^{-1}$ and 915 spectra provides good evidence for $\mathrm{v}(\mathrm{Si}-\mathrm{OH})$ and $(\mathrm{OH})$ respectable out of the plane. Also, at 1105 $\mathrm{cm}^{-1}$ is concerned with Si-O-Si and Si-O-C vibrations. There is a high-intensity absorbency at $1740 \mathrm{~cm}^{-1}, \mathrm{a}$ spectrum corresponding to the $\mathrm{v}(\mathrm{C}=\mathrm{O})$ group vibration, which is shifted by a combination of organic carbon chain graphene. The explanation for the spectrum of PDMS/graphene detection signals is that it is assigned at $1257 \mathrm{~cm}-1$ and $1099 \mathrm{~cm}^{-1}$ inclusive Si-C stretching vibration. The other reason for forming the matrix polymer or composites matrix is that no spectra appear. Functionalized graphene is not found between 790 and $950 \mathrm{~cm}^{-1}$, which means coordination of the bond related to Si-OH groups.

Figure 3 shows a comparison between different composites PDMS/graphene FTIR spectra. We found two spectra at 845 and $1585 \mathrm{~cm}^{-1}$ for the carbon structure of carbon in graphene, according to Kastnert (1994) and Saito (1998). These correspond to $\mathrm{v}(\mathrm{C}=0)$ and a peak of $1743 \mathrm{~cm}^{-1}$ at typical carboxyl moieties. Another carboxyl group makes a slight appearance around to $1346 \mathrm{~cm}^{-1}$. A weak peak was noticed at $1575 \mathrm{~cm}-1$, appoint to $-\mathrm{C}=\mathrm{C}$ in the spectrum. It might be resonance phenomena inside graphene ring related to electron transfer or $\pi-\pi$ bond interface interaction between graphene structure and $\mathrm{SiO}_{3}$ of PDMS polymer at band $785 \mathrm{~cm}^{-1}$ and 915 spectrum -this is great evidence that v (Si-OH) and v $(\mathrm{OH})$ is respectable out of the plane. Also, at $1105 \mathrm{~cm}^{-1}$ is concerned for Si-O-Si and Si-O-C vibrations. Highintensity absorbents at $1740 \mathrm{~cm}^{-1}$, a spectrum corresponding to $\mathrm{v}(\mathrm{C}=0)$ group vibration, were shifted by a combination of organic carbon chain Graphene. The explanation for the spectrum of PDMS/graphene detection signals is assigned at $1257 \mathrm{~cm}^{-1}$ and $1099 \mathrm{~cm}^{-1}$ inclusive Si-C stretching vibration. The other reason for forming the matrix polymer or composites matrix is that no spectra appear. Functionalized graphene is not found around 790 and $950 \mathrm{~cm}^{-1}$, which means coordination bonds related to Si-OH groups. 
On the other hand, structural features of the copolymers were established by FT-IR spectroscopy. Figure [3] display the FT-IR spectra of the copolymers as an example. There is no obvious variance of intensity, and the band absorption positions are found between the block copolymers and are randomly segmented.

\section{Raman Spectroscopy.}

We used Raman spectroscopy as another confirmation technique besides IR. It is a nondestructive technique that gives related structural information on carbon-skeleton materials or polymers. Raman spectroscopy of PDMS-graphene composite shown in Figure 4 was carried out using a laser (wavelength $532 \mathrm{~nm}$ ). The carbon group for the PDMS-peak wavelength spectrum is situated between $1300-1400 \mathrm{~cm}^{-1}$ and peaks slightly around $1550-1615 \mathrm{~cm}^{-1}$ for characteristic peaks of graphene Nano powder.[58] There is a proportional relationship between the intensity of graphene and PDMS polymer carbon structures, and we can demonstrated resonating charge formed on carbonyl group, lead to starched $\mathrm{C}=0$ saturated $\pi-\pi$ bond to $n-\pi$ in excited state. The increasing intensity with more graphene inside the polymer matrix demonstrated the well-dispersed and uniform distribution of graphene in a PDMS polymer cross-section. Also, there are considerable and progressive changes of intensity and widening of PDMS characteristic peaks before and after mixing with Nano powder Graphene, confirmed with TEM analysis, shown in Figures 7-9.

Figure 5 displays the spectrum intensity for nanoparticles (Ag and $\mathrm{Cu}$ ) on the surface of PEI (polyethyleneimine) with spread speak appearing for PEI structure, especially for the (NH) amines groupconfirming the assembly of nanoparticles on the PEI polymer. We also used UV spectrum analysis for a more detailed understanding.

To be more accurate, we use another optical characteristic for the prepared composite polymer. UV spectroscopic has been conducted to measure both direct and diffused light. Figure 7 shows that various spectrum absorbents at different wavelengths are a concept of Lambert's law. By comparing three spectra of absorbance PDMS/graphene, NPs/PEI, and copolymers, we found the absorbent properties change intensity. There is significant evidence that the nanoparticles $\mathrm{Ag}, \mathrm{Cu}, \mathrm{Al}$ ( suspended in electrolyte solution ), and Nano graphene filled the transmitted space (gaps), and the recorded height transmitted and disappears in other peaks in our structure. On the other hand, there is another opinion explained, a large amount of graphene doping will produce fluorescence quenching, and only at a certain dose can graphene contribute to the improvement of optical properties. Therefore, there is no explanation for the generation and disappearance of $\mathrm{Ag}$ and graphene spectra. [59]

\section{SEM Characteristics}

Scanning electron microscopy (SEM) SURFACE morphology was conducted using field emission Scanning Electron Microscopy involving a Quanta TM 3D FEG (FEI Company, USA) apparatus. All SEM 
images were created by an Everhart Thornley Detector (ETD) designed at a voltage of $5 \mathrm{e} 30 \mathrm{kV}$.

A scanning electron microscope (SEM) has been used to characterize the morphological surface features' cross-section of each PDMS and PEI, SEM. Figure 6 shows that both of the polymers' surfaces are smooth without any cracking or deformation compared to Figures $6 \mathrm{a}$ and $6 \mathrm{~b}$, which shows many cracks on the surface of different composite polymers varnished with graphene nanotubes and numerous nanoparticle conductive metals. Figure 6(b) displays a graphene/PDMS composite matrix with some defection and bending deformation on the composite composition. It is a good indicator that the new composite will be extremely flexible and wearable due to the PDMS' nature and because it is well stamped with graphene in the PDMS form. In the original PDMS, the SEM images are tidy and unruffled (without gaps or empty filler). One advantage of PDMS is that it might be subject to an electrostatic charge or polarity between the sio2 group and different nanoparticles when arranged in different shapes, as shown in Figure 6b.

On the other hand, when the same description is applied to the PEI polymer before grafting nanoparticles, SEM image $6 a$ shows that the SEM surface is smooth without any fractures or faults. Figures $6 \mathrm{a}$ and $6 \mathrm{~b}$ show the SEM micrographs of the cross-section typically look like the previously prepared composites recorded before the literature review. There is an uncommonly uniform dispersal of graphene in some parts of the figure. Overall, this confirms that there is good compatibility dispersion between the two phases of the mixture. Throughout SEM morphology characterize , we also noticed random distribution of Graphene as wall Metals Nano particles helps to improve transfer electric charge on composite structure

\section{TEM Characterization.}

All analyses were carried out by transmission Electron Microscope model H-9500 operated at $100-300 \mathrm{kV}$ TEM accelerated electron gun Panorama LaB6, with a high diffraction pattern. Specimens were divided into single crystal silicon ( $\mathrm{Si}$ ) and quickened at a voltage range between $40 \mathrm{Kv}$ to $100 \mathrm{Kv}$. A high-resolution camera with a diffraction length of $0.5 \mathrm{~m}$ and a magnification between $18 \times$ and $450,000 \times$ was used with the resolution (objective lens) set to $0.5 \mathrm{~nm} / 5.0 \mathrm{a}$ (point), $0.34 \mathrm{~nm} / 3.4 a ̊$ (line).

\section{Composite PDMS / Graphene.}

The images display excellent dispersal and the coalition of Nano Graphene in a long unfilled space of PDMS polymer. There is a big change between Figures $7 \mathrm{a}$ and $7 \mathrm{~b}$, which confirms our explanation. Furthermore, the change confirms that despite the existence of the PDMS component and good distribution of graphene inside the PDMS matrix, it will prevent agglomeration or sedimentation during the process, which leads to uneven physical properties of the composites. The TEM image indicates that the graphene nanostructure's walls are heterogeneous, rough, and spotted with extra materials compared to pure PDMS, as shown in Figure 7a. We considered that some of the aggregation or deposition of 
graphene on the surface area of PDMS is rough in some parts and uniform in other parts of PDMS due to the preparation methods (density or concentration overview).

\section{Graphene and (Ag, $\mathrm{Cu})$ NPs assembled on PEl.}

Figures $8 \mathrm{a}$ and $8 \mathrm{~b}$ show that TEM contrast in PEI/NPs polymer is accomplished via silver particles assembled on the surface of PEI due to the Ag reflection energy atom. This makes it easier to create bonds between amines groups and sliver atoms by gaining or losing electrons between two species. The size of $\mathrm{Ag}$ and $\mathrm{Cu}$, around 10- $25 \mathrm{~nm}$, causes filling in the PEI matrix cross-section. Furthermore, the homogeneity of PEl makes it easy to suspend fine nanoparticles in the solution. Also, Figure 8b indicates grafting nanoparticles (silver and copper) inside PEI polymer. It could be reforming new bonds between a pair of electrons on $\mathrm{N}$-atoms and metal atoms of silver and copper particles through a metallic bond or galvanic bridge $\mathrm{Cu} / \mathrm{Cu}+/ / \mathrm{Ag}$ - / Ag. Regarding Figure 8a. we noticed Ag and CCu's distribution.

\section{Composites PDMS-g-PEI}

TEM characterization is used to investigate and estimate the change of surface morphology of different prepared materials (Graphene-PDMS, PEI-NPs, and Copolymer PEI-g-PDMS). Figures 9a and 9b illustrate the composition and dispersion of nanographene in the filler space of PDMS compared to Figure 6b, where it appears smooth without any flocculation or deposition. The surfaces show good dispersion of layered graphene into a homogeneous PDMS-urea copolymer solution of PDMS-g-PEI. A TEM image is shown in Figure 9a. NPs and graphene particles were recorded by distributed platelet shape with lower dimension than expected due to the formation of new composites inside polymers. Graphene-Cu or graphene-Ag composites or could be present because NPs spread on graphene surfaces, which prevents them from appearing in a large amount in Figure 9b. Graphene Nanomaterials have good electric properties because charged electrons move easily through carbon by forming resonance outside of the bonds $(\mathrm{C}=\mathrm{C})$ that transfer the electrical charge $\mathrm{p}$-hole to permit electrical conductivity

Furthermore, the TEM image in Figures 9a and 9b explains both polymers' dispersal mechanismintegrated to form one copolymer without any distortion or voids. We believed the nanoparticles $(\mathrm{Ag}, \mathrm{Cu}$, and graphene) were chosen because each one has a unique physical and chemical property for forming chelating or bonded reactions together or with polymers carbon skeleton. Perfect PDMS /composites matrices can be in effect processed via the solution preparation casting and curing.

Figures $9 \mathrm{a}$ and $9 \mathrm{~b}$ show that the copolymer (PEI-g-PDMS) was formed with a highly diverse distribution of graphene, silver, and copper inside the matrix to form new composites copolymer, which is flexible, stretchable, and conductive.

\section{Particle size analyzer}


Zetasizer Nano $\$ 90$ (Malvern) modal Nano $\$ 90$ analyzer carried out a particle size analysis on the liquid phases. It is operated by Red laser $(632.8 \mathrm{~nm}, 4 \mathrm{~mW})$ and used a Zetasizer instrument that works at a receptor angle equal to 90 degrees to make it easy to investigate and estimate particles suspended inside the liquid phase located between $1 \mathrm{~nm}$ to 5 microns in diameter. Moreover, it is considered an important tool to evaluate and understand our colloidal solution and charge its physical properties, rheology behaviors, capacity, and efficiency ions charge, depletion, deposition, or precipitated particles. Figure 10 shows that the silver and copper nanoparticles are spread uniformly and suspended over the whole polyethyleneimine phase, which is good evidence of a new matrix's complete miscibility without any deformation. Furthermore, new sites or bonds will form. In addition, with the average volume of the particles at $193 \mathrm{~nm}$, it is easier to carry a charge.

Figure 10a shows that though the particle size is somewhat larger at $920 \mathrm{~nm}$, it might be related to the electrostatic or inter-inter Vander Waals force between graphene depletion or its agglomeration a TEM of surface morphology confirmed it. This showed good dispersal in some areas and flocculated in PDMSgraphene. However, it could be caused by a chain of a double layer (ions charge) forming from outer's layers of graphene walls, which makes tubes (resonance $\pi-\pi$ bond). This will be the main reason for the augmentation of conductivity in the whole final composite copolymer.

An EDAX analysis was done for composite copolymer (PDMS-g-PEI) to illustrate the main composition of impregnated nanoparticles inside the copolymer skeleton structure. There are copper, silver, and carbon (Graphene), confirmed by previous analysis recorded in Figure 12. The ion coupled plasma (ICP) for a sample of PEI-NPs contains the same elemental silver and copper composition, thus providing good evidence of the copolymer preparation (PDMS-g-PEI).

\subsection{Mechanicals characterization.}

The self-healing process and the tensile test are important methods to investigate our co-part polymers composites' mechanical properties. Figure 13 shows large differences before and after a combination of copolymers (PEI-NPs and PDMS-graphene) form one block copolymer. In Figure 12, two polymers are compared by increasing the tensile strain by $10 \%$ compared to the PDMS /graphene polymer. The results also expose that the self-healed composite copolymer's tensile strength regains up to $90 \%$ of its original value.

\subsection{Dielectric Substrate PDMS characterization.}

Dielectric phenomena is one specific characterize for PDMS substrate and should take in our consideration. Specifically, Dielectric properties PDMS substrate was deliberated using dielectric analyzer (Novocontrol BDS $20 \mathrm{GmbH}$ ),ETS Montreal. Samples were located in a vacuum chamber to 
avert errors during the measurements. By applying plasma treatment without any affect the dielectric response like other types of polymers reported in previous literature [60].

With Referring to figure (14) points out the dielectric Properties pure PDMS .due to the polarization of function group Si-O-Si bonding, which appears as neutral, due to stability of a structure without external effect like bonding, interaction force or reacted with another active atom, that means PDMS without any treatment ( grafting, assembling and block ), which are responsible for enhancing of activity and conductivity of dielectric material. The measurement was based on the amount of the real and the imaginary value, which is relative to the relative permittivity of a pure structured PDMS material in a frequency range between $1 \mathrm{~Hz}$ to $10^{6} \mathrm{~Hz}$ at ambient temperature However, homogeneous of PDMS nature is one important case to give details of nonconductive is 2.69 , which appear in figure (14 )

\section{Conclusion}

To conclude, the copolymers' unique characteristics-robustness, flexibility, and good conductivity depend on the type of assembled nanomaterials, physical behaviors, and the chemicals created by bonding or chelating. The field of assembling or grafting carbon nanomaterials to diversify their properties creates applications in various fields. We created a flexible antenna that is easily applicable and non-toxic. We recorded the effect of grafting or combining nanoparticles graphene and copper and silver as a sandwich. We completely changed a new composite (copolymer) with nanostructures, such as graphenecarbon nanoform structures, by an sp2 hybridization mechanism. Using organosilanes in addition to PEI (polyethyleneimine) to broaden carbon nanomaterial behaviors and properties is an important way should be overwork.

The stretchable and formable patch antenna focuses on the material sandwich used in fabrication, such as PDMS-graphene/PEI-NPs composites.

We have characterized, fabricated and investigated, its improvement in all physical properties. For instance, we carried out electrochemical characteristics like EIS, impedance measurement to estimate new composites' conductivity, and comparison between initial and final product. In some of the mechanical tests applied to the copolymer structure, we noticed the new copolymer (PDMS-g-PEI) has healing and tension strain. Furthermore, numerous experiments and analyses have been conducting to prove the composite's composition, surface morphology, and nanoparticles distribution. In this way, we created a flexible, wearable electronic device that can be used in the future.

\section{Abbreviations}

PDMS Sylgard 184), or polydimethylsiloxane

EIS Electrochemical Impedance Spectroscopy

CV cyclic voltammetry 
DSC Differential scanning calorimetry

TEM Transmission electron microscopy

UV Ultraviolet-visible spectroscopy

MEMS Microelectromechanical systems

AC alternative -current

OCV Open cycle volt

SEM scanning electron microscopy

NPs- Nano particles

PEI Polyethylenimine

ICP ion coupled plasma

\section{Declarations}

\section{- Conflict of Interest}

The authors declare no conflict of interest.

There is no Funding related that project

\section{- Authors' contributions}

Ameen Fabrication of Antenna, Measurement and characterization composite materials, collecting date . Investigation of Antenna device applicable, instruments handing and analyzing the data, manuscript writing had been carried out Dr Nedil Mourad . Conceptualization and manuscript reviewing and editing. Measurement of the performance antenna device and analysis. Dr. Fouad Erchiqui Under his supervision and revised the manuscript (Language editing). All authors read and approved the final manuscript

\section{- Acknowledgements}

I would like to thank my former and current lab members Prof. Mohmed siaj for his assistance and expertise in helping complete my research work in his laboratory in Nano-QAM , UQAM university ,Montreal ,Canada

\section{- Availability of data and materials}

All data generated or analyzed during this study are included in this published. 


\section{References}

[1] Noh, J. S. (2016). Conductive elastomers for stretchable electronics, sensors and energy harvesters. Polymers, 8(4), 123.

[2] Woo, J. Y., Kim, K. K., Lee, J., Kim, J. T., \& Han, C. S. (2014). Highly conductive and stretchable Ag nanowire/carbon nanotube hybrid conductors. Nanotechnology, 25(28), 285203.

[3] Zhang, S., Li, Y., Tian, Q., Liu, L., Yao, W., Chi, C., ... \& Wu, W. (2018). Highly conductive, flexible and stretchable conductors based on fractal silver nanostructures. Journal of Materials Chemistry C, 6(15), 3999-4006.

[4] Shin, M. K., Oh, J., Lima, M., Kozlov, M. E., Kim, S. J., \& Baughman, R. H. (2010). Elastomeric conductive composites based on carbon nanotube forests. Advanced materials, 22(24), 2663-2667.

[5] Cai, L., Zhang, S., Miao, J., Yu, Z., \& Wang, C. (2016). Fully printed stretchable thin-film transistors and integrated logic circuits. Acs Nano, 10(12), 11459-11468.

[6] Kim, K. S., Zhao, Y., Jang, H., Lee, S. Y., Kim, J. M., Kim, K. S., ... \& Hong, B. H. (2009). Large-scale pattern growth of graphene films for stretchable transparent electrodes. nature, 457(7230), 706-710.

[7] Stankovich, S., Dikin, D. A., Dommett, G. H., Kohlhaas, K. M., Zimney, E. J., Stach, E. A., ... \& Ruoff, R. S. (2006). Graphene-based composite materials. nature, 442(7100), 282-286.

[8] Yan, C., Wang, J., Kang, W., Cui, M., Wang, X., Foo, C. Y., ... \& Lee, P. S. (2014). Highly stretchable piezoresistive graphene-nanocellulose nanopaper for strain sensors. Advanced materials, 26(13), 20222027.

[9] Chen, M., Zhang, L., Duan, S., Jing, S., Jiang, H., \& Li, C. (2014). Highly stretchable conductors integrated with a conductive carbon nanotube/graphene network and 3D porous poly (dimethylsiloxane). Advanced Functional Materials, 24(47), 7548-7556.

[10] Yakuphanoglu, F., \& Şenkal, B. F. (2007). Electronic and thermoelectric properties of polyaniline organic semiconductor and electrical characterization of AI/PANI MIS diode. The Journal of Physical Chemistry C, 111(4), 1840-1846.

[11] Fu, Y., \& Manthiram, A. (2012). Enhanced cyclability of lithium-sulfur batteries by a polymer aciddoped polypyrrole mixed ionic-electronic conductor. Chemistry of Materials, 24(15), 3081-3087.

[12] Borah, D., Ozmen, M., Rasappa, S., Shaw, M. T., Holmes, J. D., \& Morris, M. A. (2013). Molecularly functionalized silicon substrates for orientation control of the microphase separation of PS-b-PMMA and PS-b-PDMS block copolymer systems. Langmuir, 29(9), 2809-2820.

[13] C.AArnold, J.D. Summers, Y.P Chen, R.H Bott, D.Chen Polymer; Elsevier, 1989, Vol. 30, pp 986-995. 
[14] Mahoney, C. M., Gardella, J. A., \& Rosenfeld, J. C. (2002). Surface characterization and adhesive properties of poly (imidesiloxane) copolymers containing multiple siloxane segment lengths. Macromolecules, 35(13), 5256-5266..

[15] E.Hamciuc,C. Hamciuc, \& Cazacu, ,Rev Roum Chim, . 2009 54, 1007-13.56-16.

[16] McGrath, J. E., Dunson, D. L., Mecham, S. J., \& Hedrick, J. L. In Progress in Polyimide Chemistry I 1999 (pp. 61-105). Springer, Berlin, Heidelberg.

(17) M. Freebody,. (Ed.). 2011. Photonics Spectra, 45(5), 45-47.

(18) Borah, D., Ozmen, M., Rasappa, S., Shaw, M. T., Holmes, J. D., \& Morris, M. A. (2013). Molecularly functionalized silicon substrates for orientation control of the microphase separation of PS-b-PMMA and PS-b-PDMS block copolymer systems. Langmuir, 29(9), 2809-2820.

(19) Mack, C. A. (2011). Fifty years of Moore's law. IEEE Transactions on semiconductor manufacturing, 24(2), 202-207..

(20) Raquez, J. M., Habibi, Y., Murariu, M., \& Dubois, P. (2013). Polylactide (PLA)-based nanocomposites. Progress in Polymer Science, 38(10-11), 1504-1542.

[21] A.Vaglio Pret, P. Poliakov ,R. Gronheid, P Blomme, M. Miranda Corbalan,W Dehaene, D. Verkest, J. Van Houdt,D. ..(2012) Microelectronic Engineering; Elsevier, Vol. 98, pp 24-2804.013.

[22] Biswas, A., Bayer, I. S., Biris, A. S., Wang, T., Dervishi, E., \& Faupel, F. (2012). Advances in top-down and bottom-up surface nanofabrication: Techniques, applications \& future prospects. Advances in colloid and interface science, 170(1-2), 2-27.

[23] Darling, S. B. (2007). Directing the self-assembly of block copolymers. Progress in Polymer Science, 32(10), 1152-1204.

[24] Li, H. W., \& Huck, W. T. (2004). Ordered block-copolymer assembly using nanoimprint lithography. Nano Letters, 4(9), 1633-1636.

[25] Kim, J. U., Lee, S., \& Kim, T. I. (2016). Recent advances in unconventional lithography for challenging 3D hierarchical structures and their applications. Journal of Nanomaterials, 2016.

[26] Ghoshal, T., Senthamaraikannan, R., Shaw, M. T., Holmes, J. D., \& Morris, M. A. (2012). "In situ" hard mask materials: a new methodology for creation of vertical silicon nanopillar and nanowire arrays. Nanoscale, 4(24), 7743-7750.

[27] Hirai, T., Leolukman, M., Liu, C. C., Han, E., Kim, Y. J., Ishida, Y., ... \& Gopalan, P. (2009). One-step direct-patterning template utilizing self-assembly of POSS-containing block copolymers. Advanced Materials, 21(43), 4334-4338. 
[28] Lee, J., Lee, P., Lee, H., Lee, D., Lee, S. S., \& Ko, S. H. (2012). Very long Ag nanowire synthesis and its application in a highly transparent, conductive and flexible metal electrode touch panel. Nanoscale, 4(20), 6408-6414.

[29] Xu, F., \& Zhu, Y. (2012). Highly conductive and stretchable silver nanowire conductors. Advanced materials, 24(37), 5117-5122.

[30] Gaynor, W., Burkhard, G. F., McGehee, M. D., \& Peumans, P. (2011). Smooth nanowire/polymer composite transparent electrodes. Advanced Materials, 23(26), 2905-2910.

[31] Arnold, C. A., Summers, J. D., Chen, Y. P., Bott, R. H., Chen, D., \& McGrath, J. E. (1989). Structureproperty behaviour of soluble polyimide-polydimethylsiloxane segmented copolymers. Polymer, 30(6), 986-995.

[32] Mahoney, C. M., Gardella, J. A., \& Rosenfeld, J. C. (2002). Surface characterization and adhesive properties of poly (imidesiloxane) copolymers containing multiple siloxane segment lengths. Macromolecules, 35(13), 5256-5266.

[33] Hamciuc, E., Hamciuc, C., \& Cazacu, M. (2009). Comparative evaluation of some properties of two poly (ether-imide) thin films with/without fluorine in the structure. Rev Roum Chim, 54, 1007-1013.

[34] McGrath, J. E., Dunson, D. L., Mecham, S. J., \& Hedrick, J. L. (1999). Synthesis and characterization of segmented polyimide-polyorganosiloxane copolymers. Progress in Polyimide Chemistry I, 61-105.

[35] Chen, G., Pei, X., Liu, J., \& Fang, X. (2013). Synthesis and properties of transparent polyimides derived from trans-and cis-1, 4-bis (3, 4-dicarboxyphenoxy) cyclohexane dianhydrides. Journal of Polymer Research, 20(6), 1-11.

[36] Krea, M., Roizard, D., Moulai-Mostefa, N., \& Sacco, D. (2004). New copolyimide membranes with high siloxane content designed to remove polar organics from water by pervaporation. Journal of Membrane Science, 241(1), 55-64.

[37] Wohl, C. J., Atkins, B. M., Belcher, M. A., \& Connell, J. W. (2012). Synthesis, characterization, topographical modification, and surface properties of copoly (imide siloxane) s. High Performance Polymers, 24(1), 40-49.

[38] Yilgör, İ., \& McGrath, J. E. (1988). Polysiloxane containing copolymers: a survey of recent developments. Polysiloxane copolymers/anionic polymerization, 1-86.

[39] Liaw, W. C., Chang-Chien, J., Kang, H., Cheng, Y. L., \& Li-Wen, F. U. (2008). A straightforward synthesis and characterization of a new poly (imide siloxane)-based thermoplastic elastomer. Polymer journal, 40(2), 116-125. 
[40] Mata, A., Fleischman, A. J., \& Roy, S. (2005). Characterization of polydimethylsiloxane (PDMS) properties for biomedical micro/nanosystems. Biomedical microdevices, 7(4), 281-293. [41] Baughman, R. H., Zakhidov, A. A., \& De Heer, W. A. (2002). Carbon nanotubes--the route toward applications. science, 297(5582), 787-792.

[42] Lee, S. H., Lee, D. H., Lee, W. J., \& Kim, S. O. (2011). Tailored assembly of carbon nanotubes and graphene. Advanced Functional Materials, 21(8), 1338-1354.

[43] Jiao, J., Zhang, H., Yu, L., Wang, X., \& Wang, R. (2012). Dispersion of carbon nanotubes with the aid of surface-active ionic liquids 1-dodecyl-3-methyl-pyrrolidinium bromide. Journal of Molecular Liquids, 171, 6-10.

[44] Coleman, J. N., Khan, U., Blau, W. J., \& Gun'ko, Y. K. (2006). Small but strong: a review of the mechanical properties of carbon nanotube-polymer composites. Carbon, 44(9), 1624-1652.

[45] Mirkhani, S. A., Arjmand, M., Sadeghi, S., Krause, B., Pötschke, P., \& Sundararaj, U. (2017). Impact of synthesis temperature on morphology, rheology and electromagnetic interference shielding of CVD-grown carbon nanotube/polyvinylidene fluoride nanocomposites. Synthetic Metals, 230, 39-50.

[46] Hamra, A. A. B., Lim, H. N., Hafiz, S. M., Kamaruzaman, S., Rashid, S. A., Yunus, R., ... \& Huang, N. M. (2018). Performance stability of solid-state polypyrrole-reduced graphene oxide-modified carbon bundle fiber for supercapacitor application. Electrochimica Acta, 285, 9-15.

[47] Li, J., Cheng, X., Sun, J., Brand, C., Shashurin, A., Reeves, M., \& Keidar, M. (2014). based ultracapacitors with carbon nanotubes-graphene composites. Journal of Applied Physics, 115(16), 164301.

[48] Hwang, J., Jang, J., Hong, K., Kim, K. N., Han, J. H., Shin, K., \& Park, C. E. (2011). Poly (3hexylthiophene) wrapped carbon nanotube/poly (dimethylsiloxane) composites for use in finger-sensing piezoresistive pressure sensors. Carbon, 49(1), 106-110.

[49] P.Pötschke, K.Kobashi, T; Villmow, T. Andres, M.C ; Paiva, J.A Covas,( 2011). Compos. Sci. Technol. 71 (12), 1451-1460.

[50] Yu, M., He, Q., Yu, D., Zhang, X., Ji, A., Zhang, H., ... \& Dai, Z. (2012). Efficient active actuation to imitate locomotion of gecko's toes using an ionic polymer-metal composite actuator enhanced by carbon nanotubes. Applied Physics Letters, 101(16), 163701.

[51] S.K Yadav, I.J .; Kim, H.I .; Kim, J..; Kim, S.M HongC.M Koo, (2013). J. Mater. Chem. C 1 (35), 5463-5470..

[52] Kazaoui, S., Minami, N., Nalini, B., Kim, Y., \& Hara, K. (2005). Near-infrared photoconductive and photovoltaic devices using single-wall carbon nanotubes in conductive polymer films. Journal of applied physics, 98(8), 084314. 
[53] Mao, G., Saboungi, M. L., Price, D. L., Badyal, Y. S., \& Fischer, H. E. (2001). Lithium environment in PEO-LiClO4 polymer electrolyte. EPL (Europhysics Letters), 54(3), 347.

[54] Kim, D., \& Yun, K. S. (2013). Patterning of carbon nanotube films on PDMS using SU-8 microstructures. Microsystem technologies, 19(5), 743-748.

[55] Liu, G. (2002). Investigation of ductile fracture under tensile high rate loading (Doctoral dissertation, Carleton University).

[56] Kurdi, J., \& Tremblay, A. Y. (2003). Improvement in polyetherimide gas separation membranes through the incorporation of nanostructured metal complexes. Polymer, 44(16), 4533-4540.

[57] Ren, J., Zhou, J., \& Deng, M. (2010). Morphology transition of asymmetric polyetherimide flat sheet membranes with different thickness by wet phase-inversion process. Separation and purification technology, 74(1), 119-129.

[58] Kim, H. S., Waqued, S. C., Nodurft, D. T., Devarenne, T. P., Yakovlev, V. V., \& Han, A. (2017). Raman spectroscopy compatible PDMS droplet microfluidic culture and analysis platform towards on-chip lipidomics. Analyst, 142(7), 1054-1060.

[59] Pan, Y., Wang, L., Su, X., Gao, D., \& Cheng, P. (2021). Nanolasers Incorporating Co x Ga0. 6-x ZnSe0. 4 Nanoparticle Arrays with Wavelength Tunability at Room Temperature. ACS Applied Materials \& Interfaces, 13(5), 6975-6986.

[60] Palmer, M. V., Thacker, T. C., Waters, W., Gortázar, C., \& Corner, L. A. (2012). Veterinary medicine international, 2012.

\section{Figures}

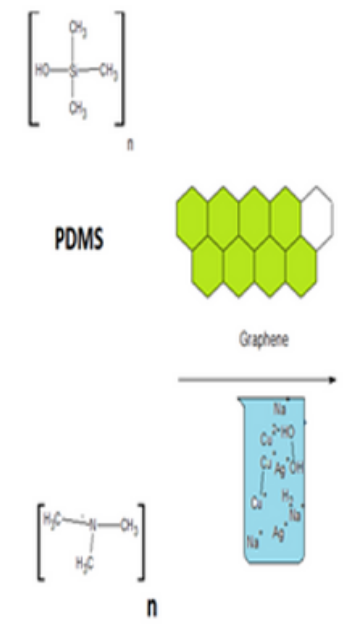

PEI

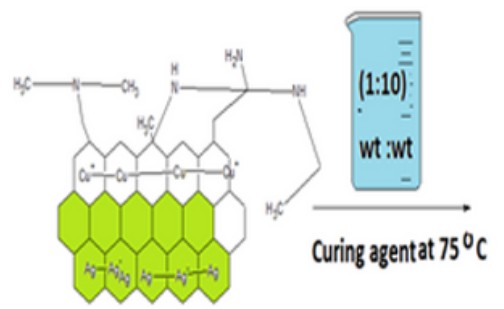

Structure copolymer PDMS -g.PEI

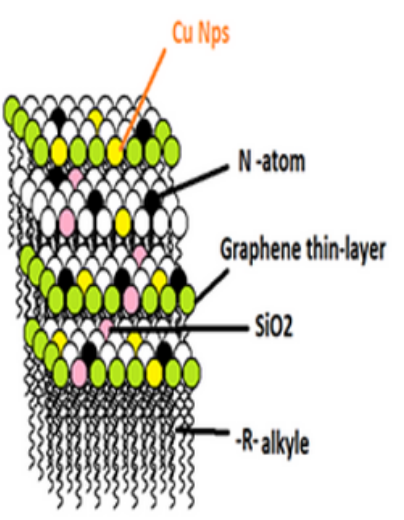

Copolymer POMS-Graphen/NPs-PEI

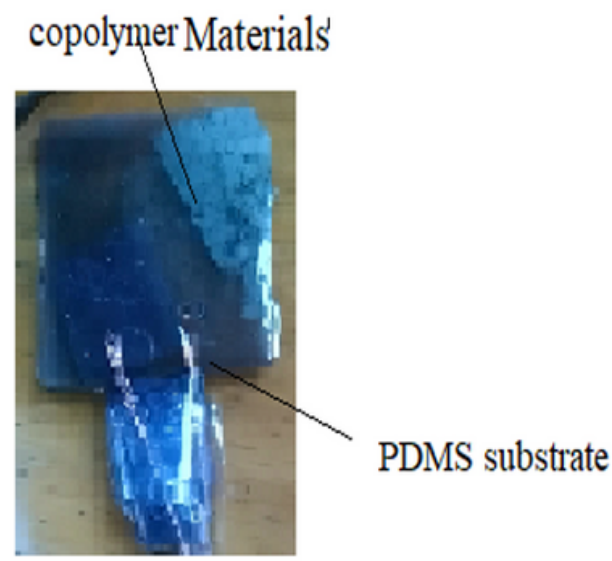

FlexibleConductive copolymer Material 
Figure 1

Pathway of copolymer PDMS - Graphene /NPs- PEI preparation.

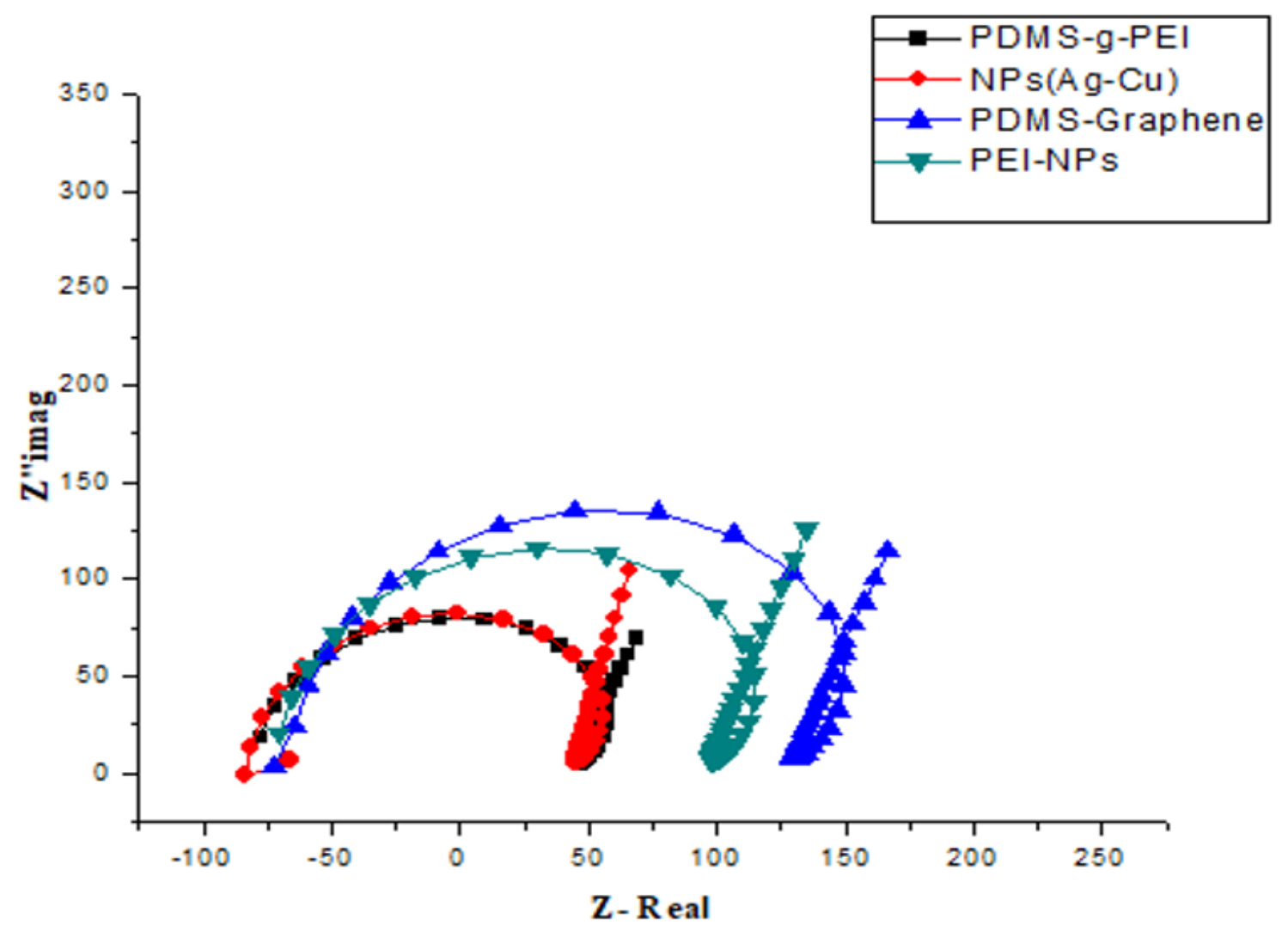

Figure 2

The impedance of different prepared solutions used to copolymer composition. 


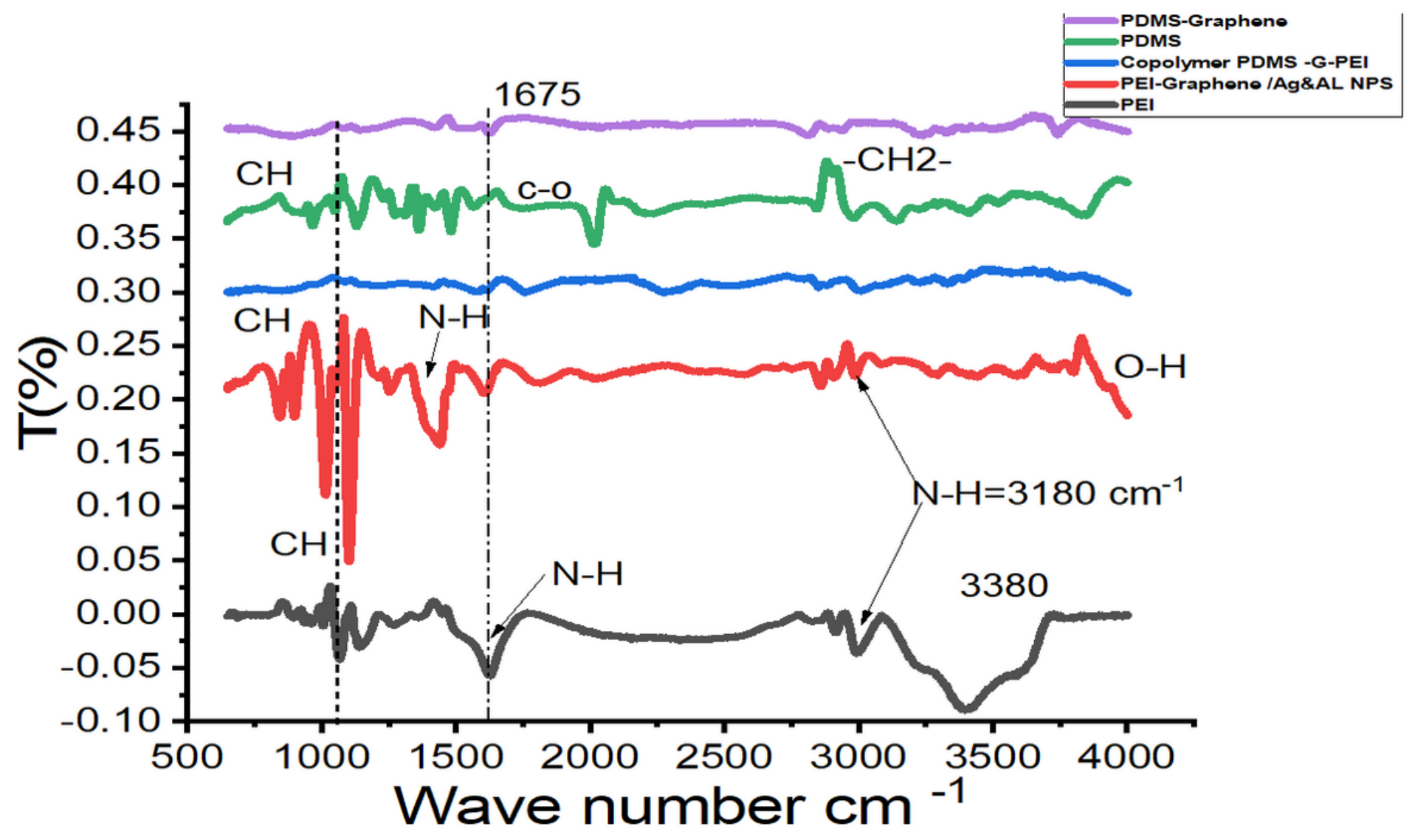

Figure 3

IR spectrum characterization 


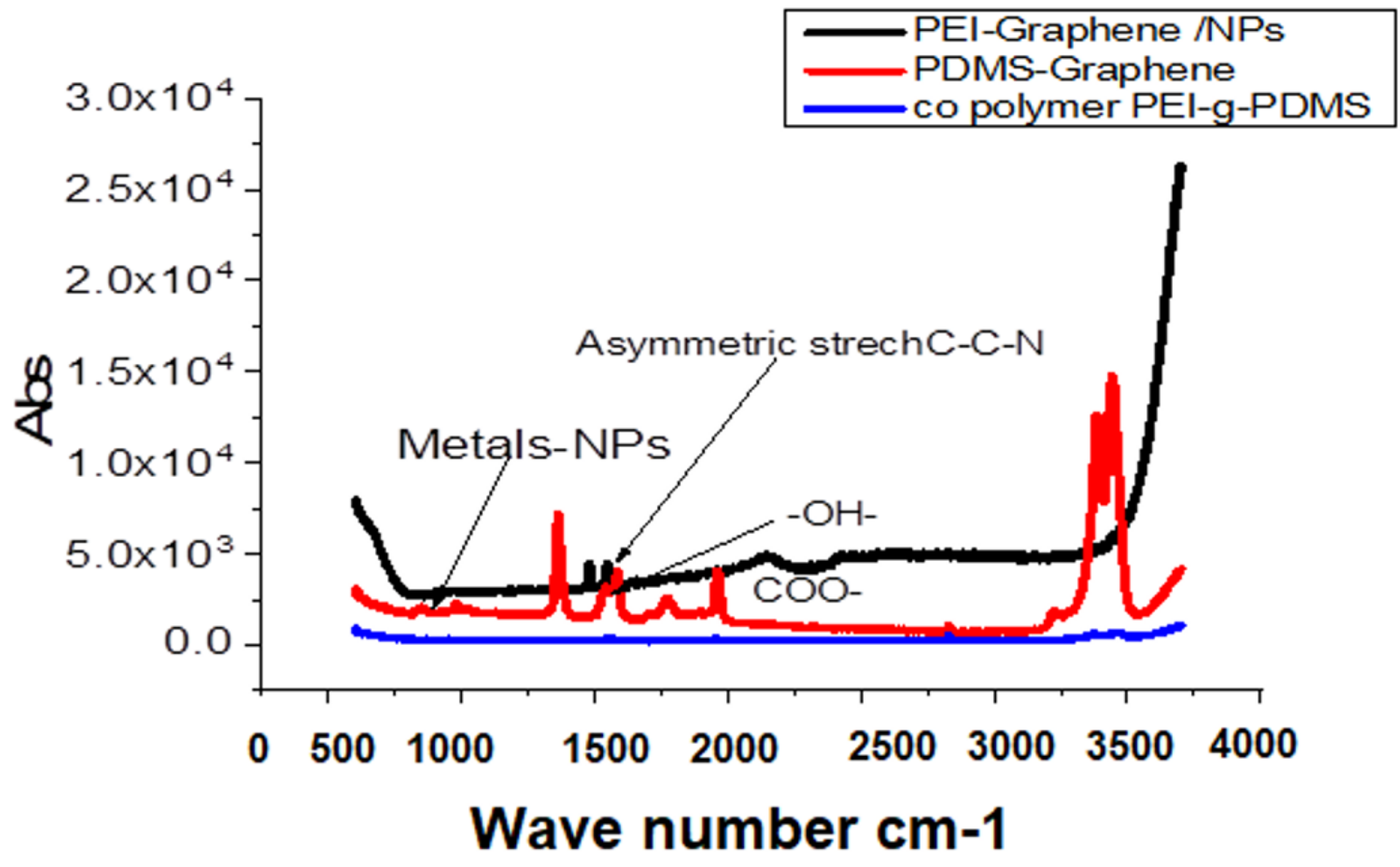

Figure 4

Raman analysis for different composites. 


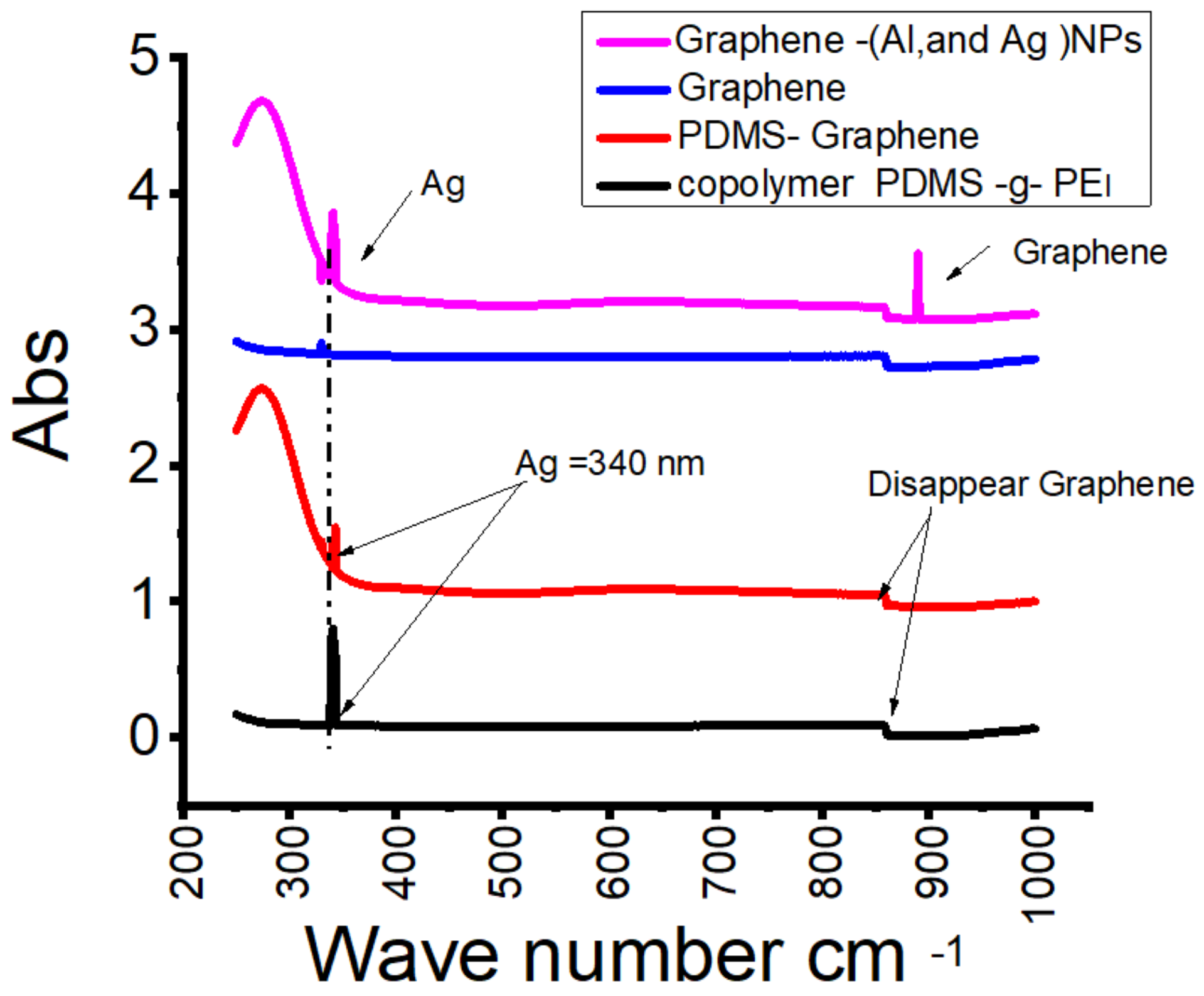

Figure 5

UV for composites structure 


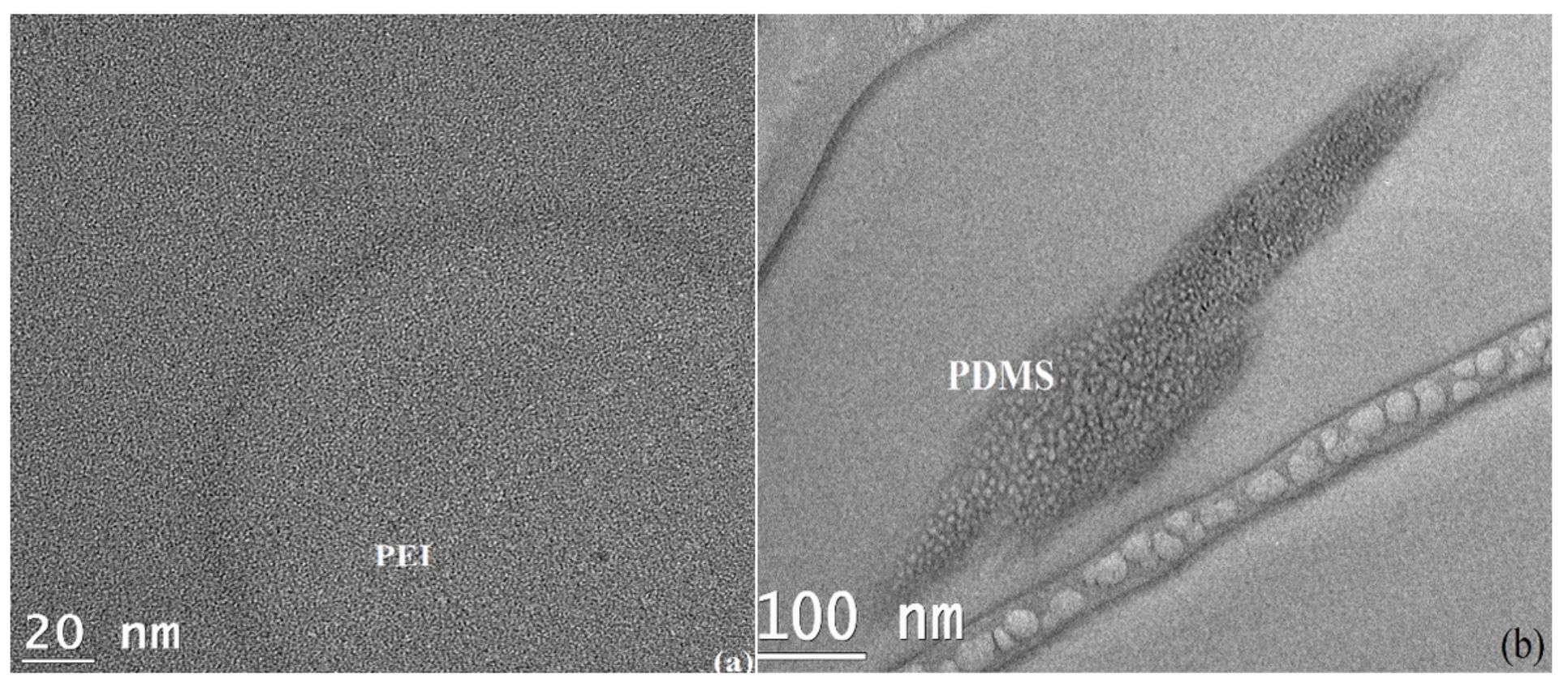

Figure 6

SEM for a) PEI b) PDMS

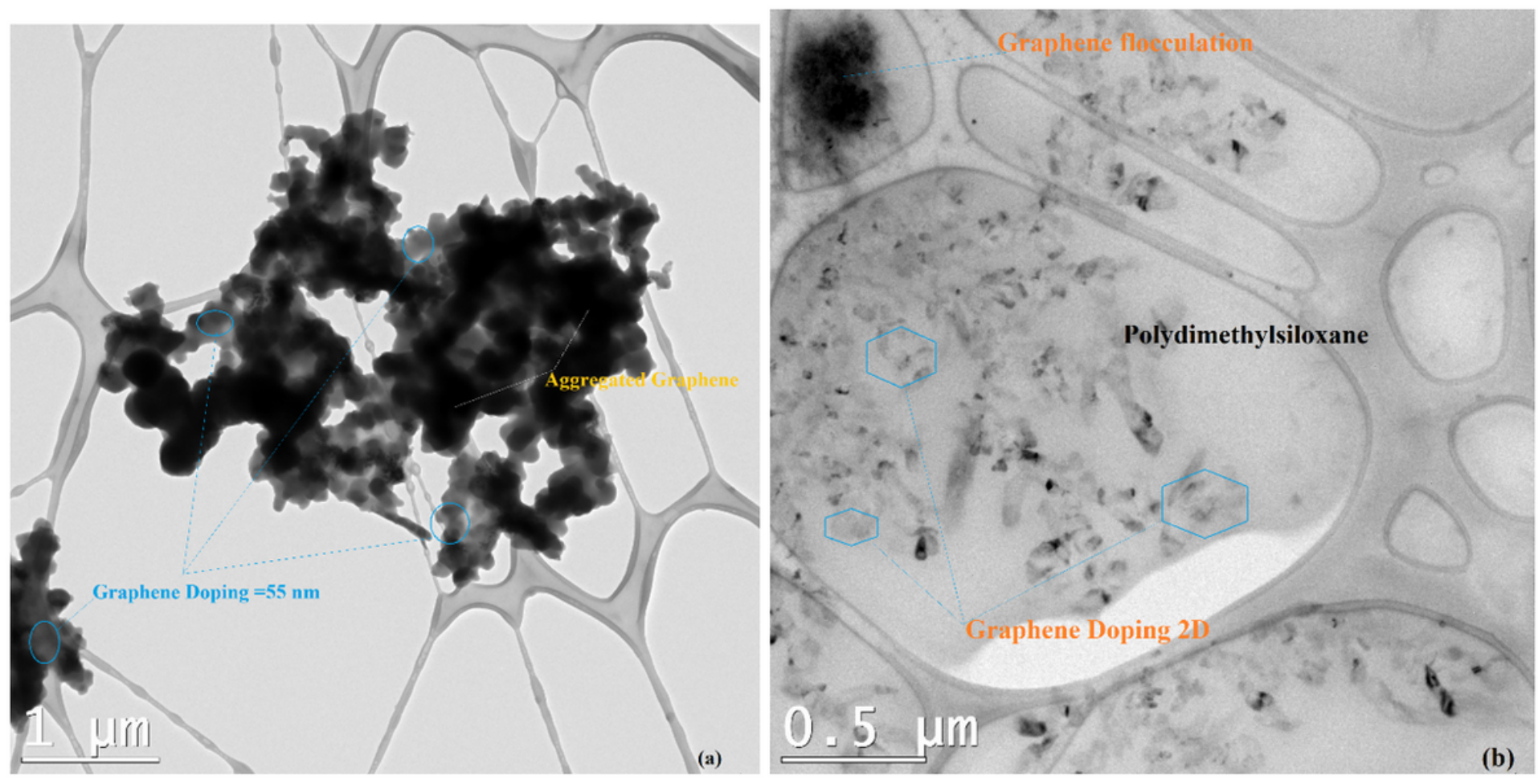

Figure 7

TEM a) Graphene b) PDMS / Graphene solution 


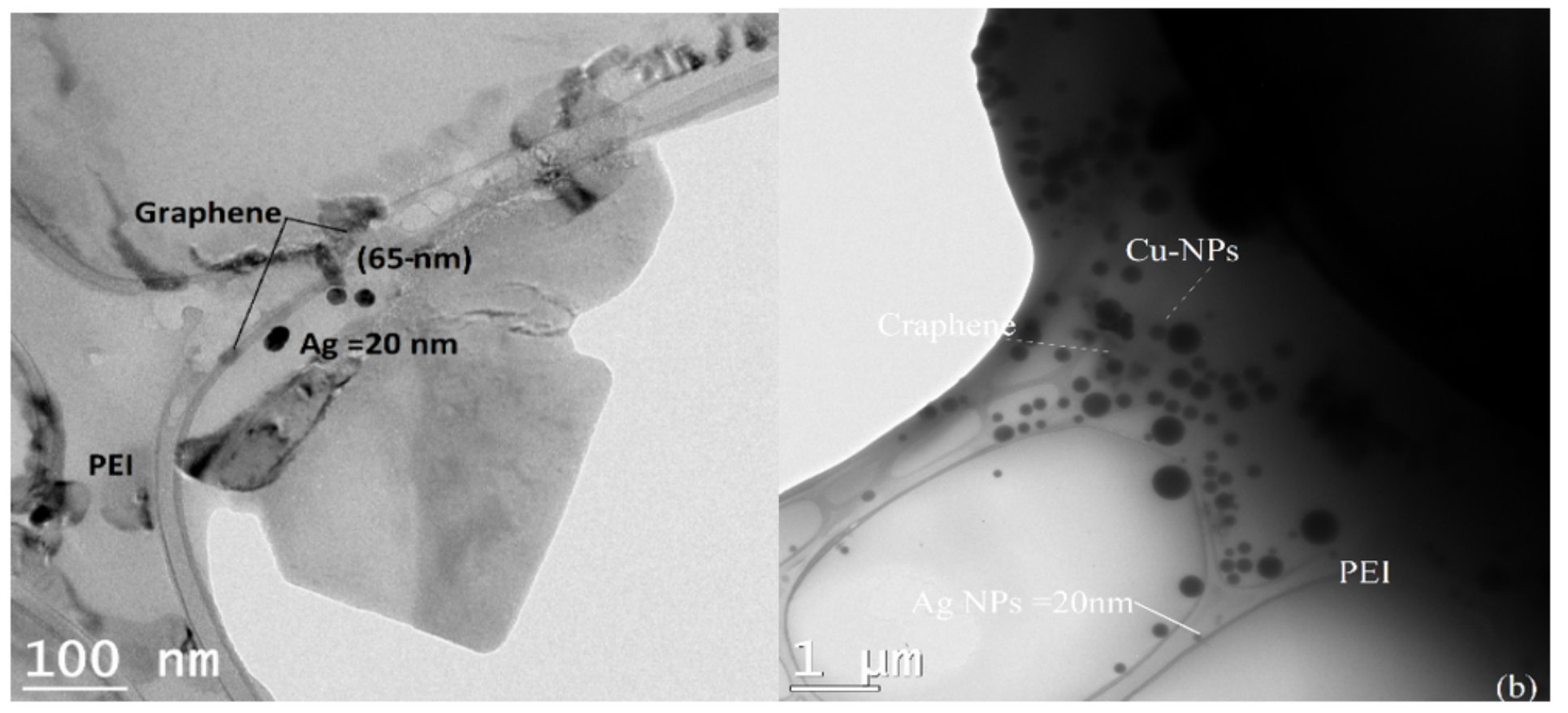

Figure 8

TEM a) PEI - Graphene b) PEI-Graphene/NPs assembled

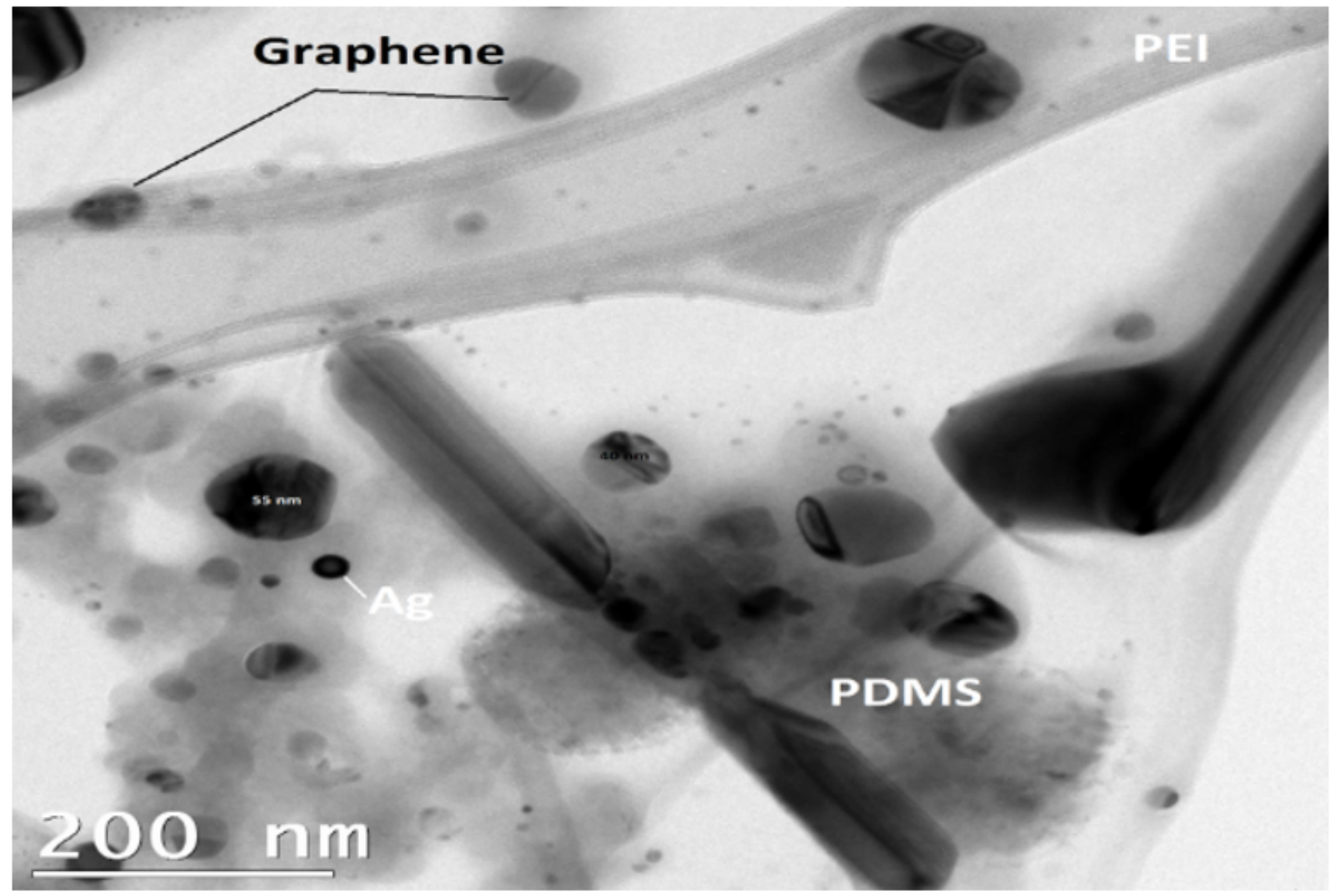


Figure 9

TEM PDMS - Graphene /NPS -PEI Co-polymer composites.

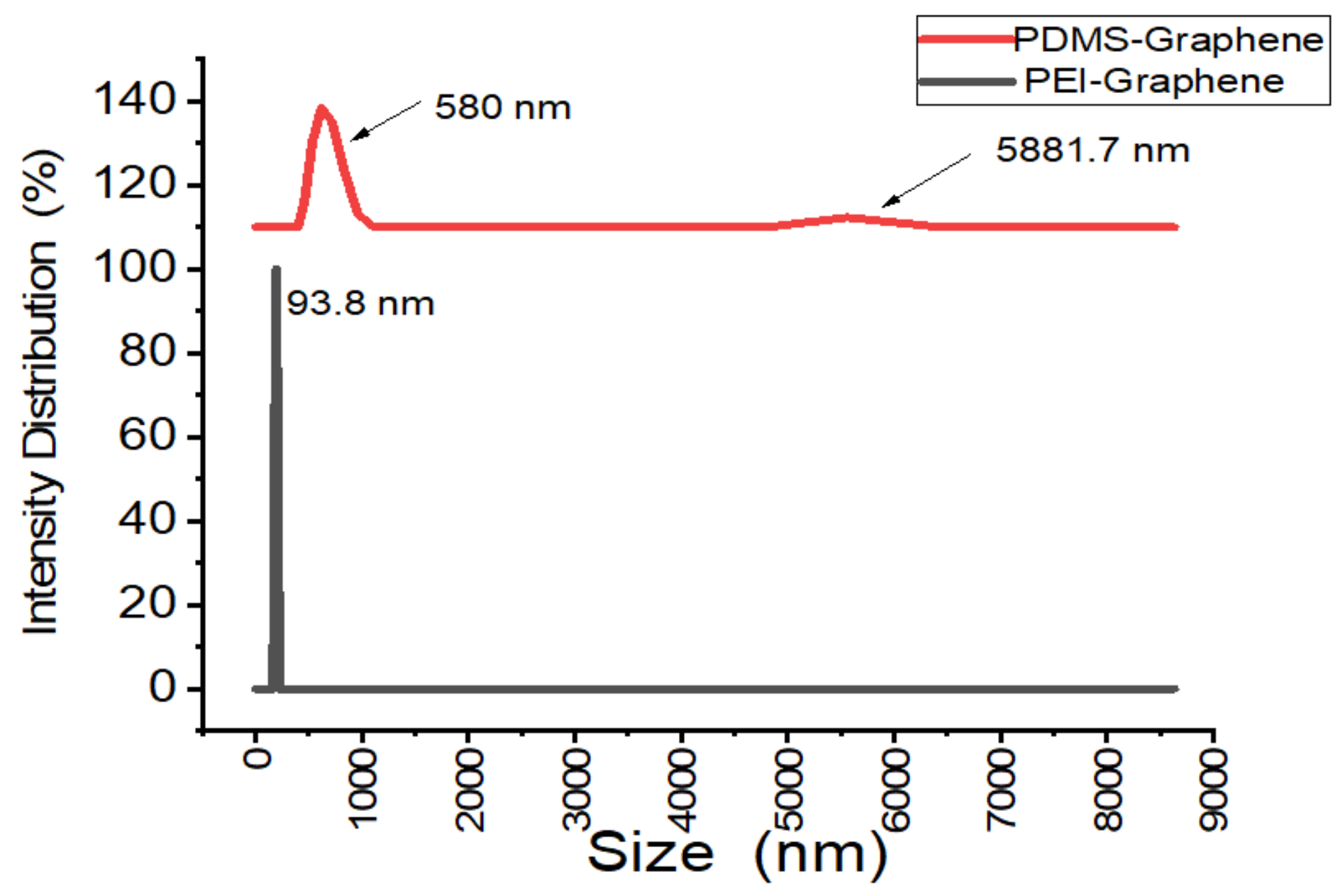

Figure 10

Particle size Analyzer a) PDMS / graphene b), PEl polymer assembled nanoparticles and graphene. 


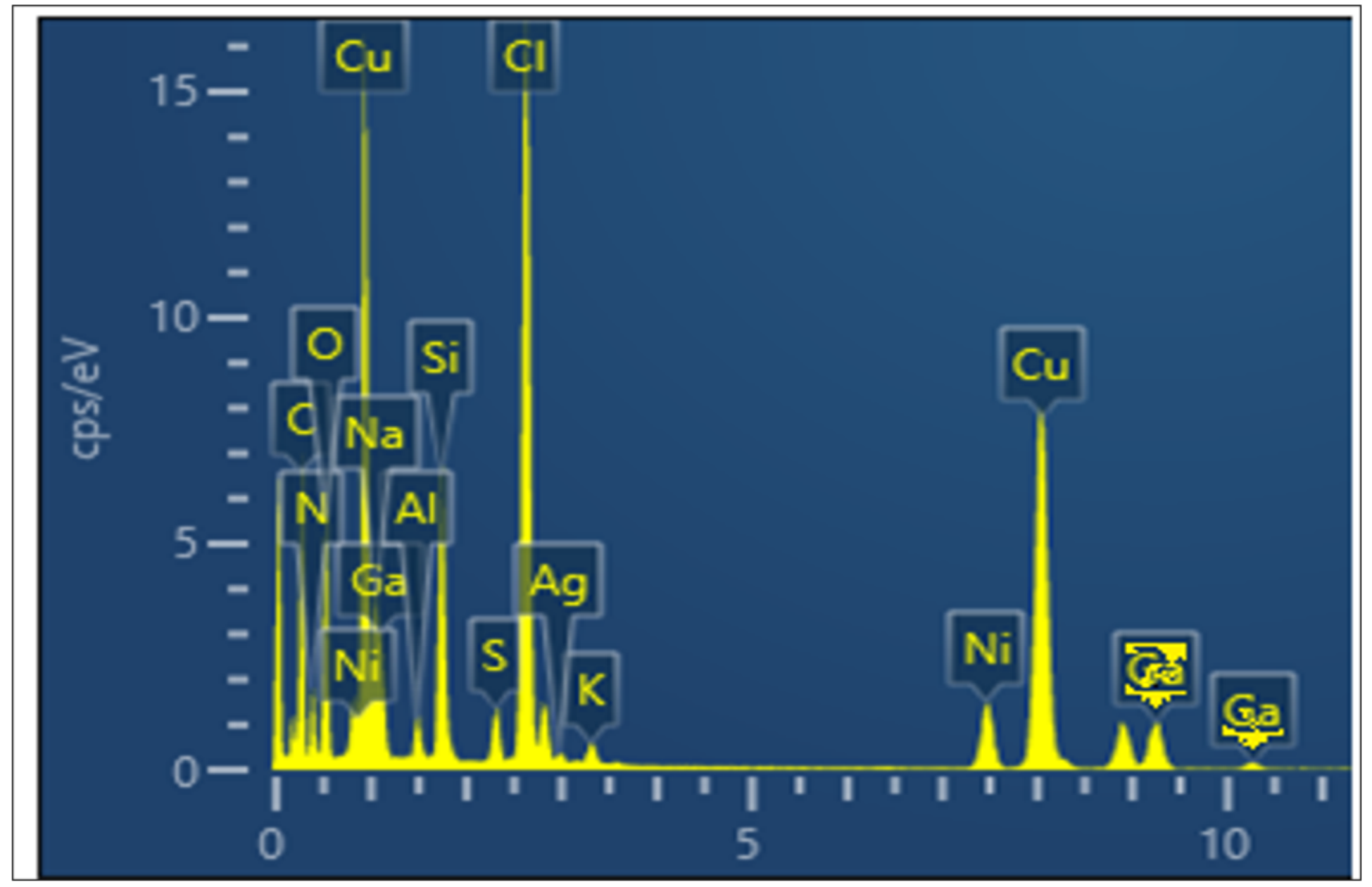

Figure 11

EDAX characterization of copolymers. 


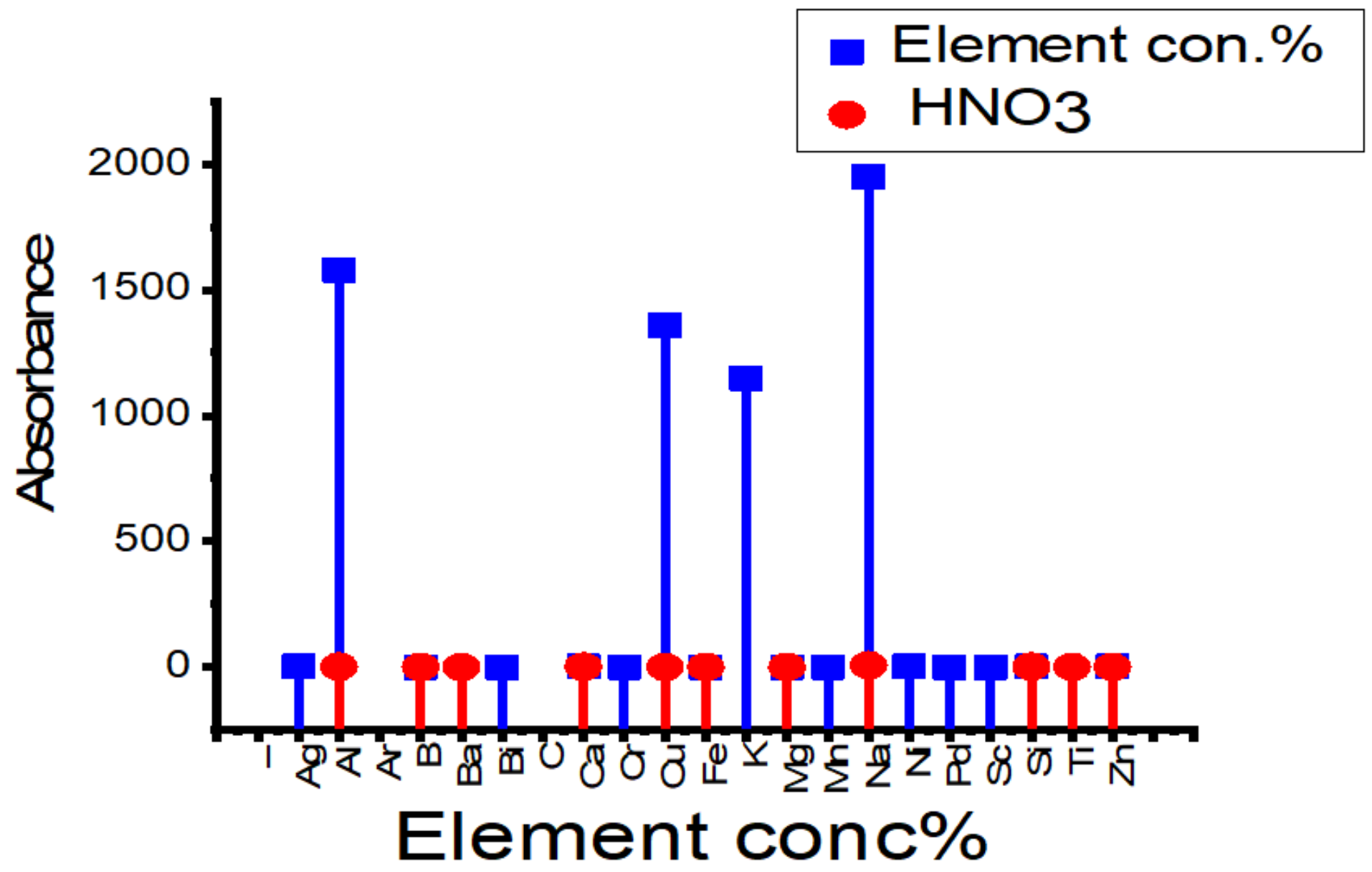

Figure 12

ICP analysis PEI-NPs. 


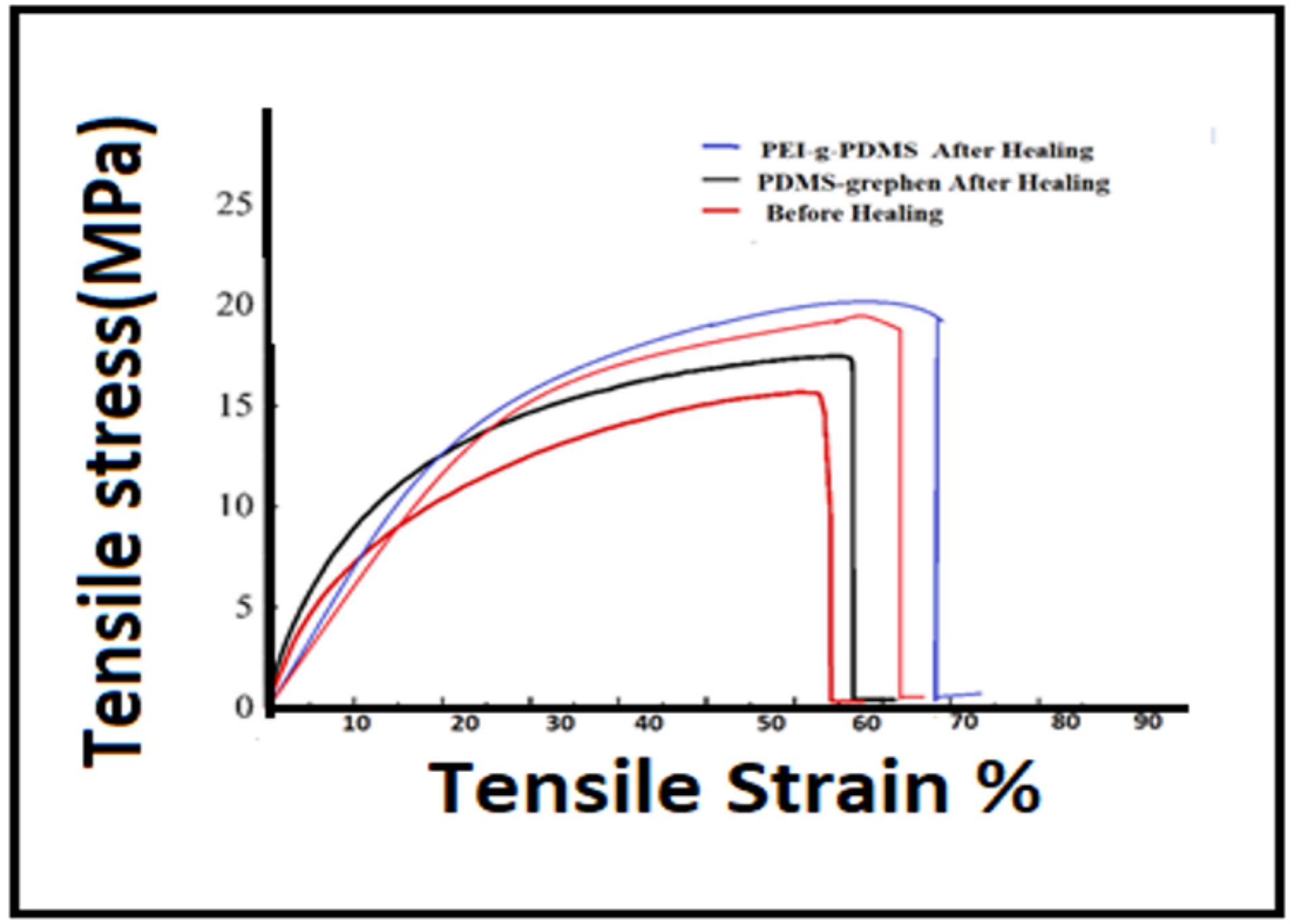

Figure 13

Stress-strain of free-standing PDMS, and co-polymers PDMS-graphene-PEl before and after the selfhealing process. 


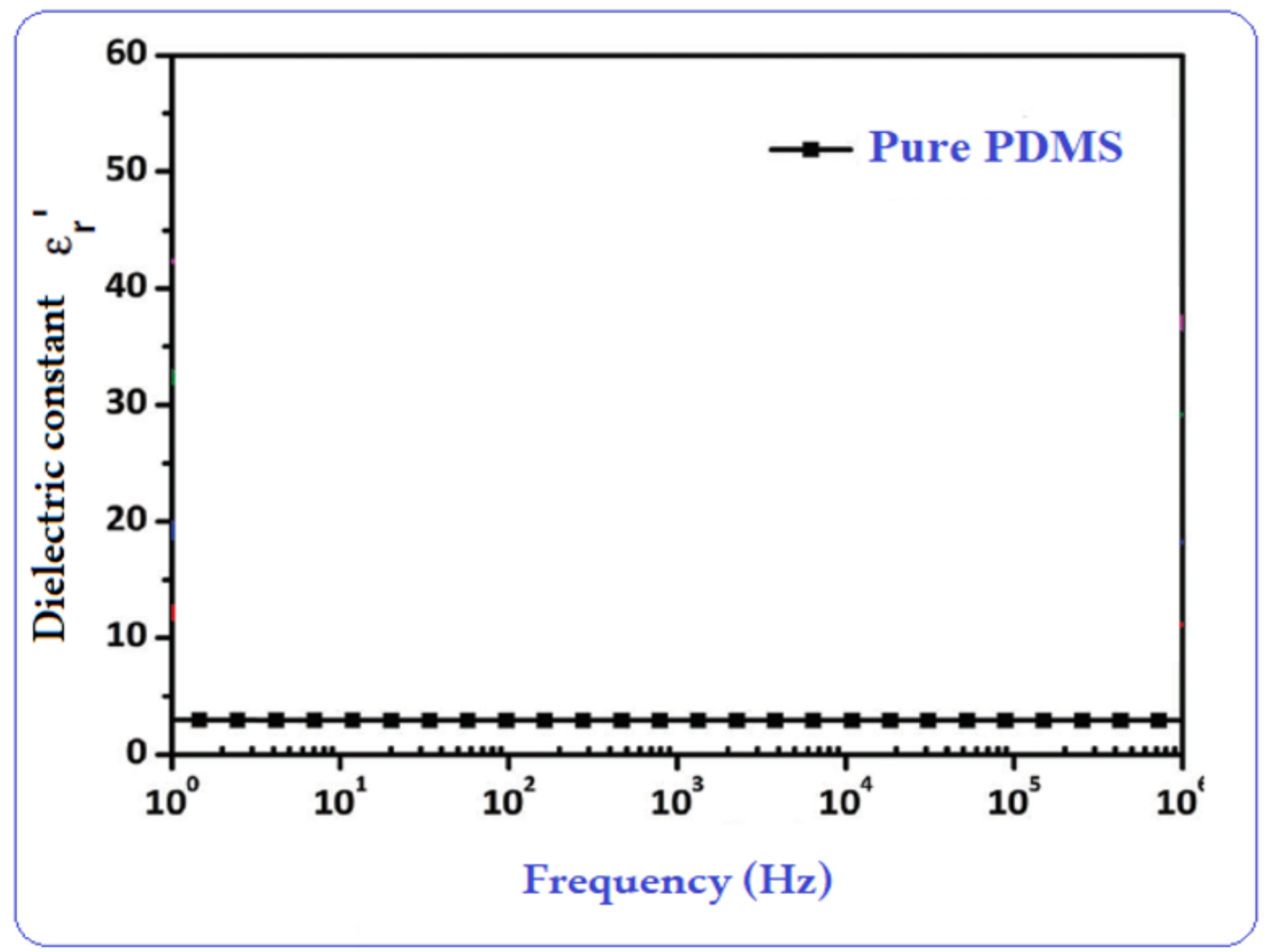

Figure 14

Dielectric constant of PDMS substrate . 